DISTRIBUTION AND ABUNDANCE OF ENDANGERED FLORIDA KEY DEER ON OUTER ISLANDS

\author{
A Thesis \\ by \\ DOMINIQUE ELIJAH WATTS
}

\begin{abstract}
Submitted to the Office of Graduate Studies of Texas A\&M University

in partial fulfillment of the requirements for the degree of

MASTER OF SCIENCE
\end{abstract}

December 2006

Major Subject: Wildlife and Fisheries Sciences 


\title{
DISTRIBUTION AND ABUNDANCE OF ENDANGERED FLORIDA KEY DEER ON OUTER ISLANDS
}

\author{
A Thesis \\ by \\ DOMINIQUE ELIJAH WATTS
}

\begin{abstract}
Submitted to the Office of Graduate Studies of Texas A\&M University

in partial fulfillment of the requirements for the degree of

MASTER OF SCIENCE
\end{abstract}

Approved by:

Chair of Committee, $\quad$ Roel R. Lopez

Committee Members, Nova J. Silvy

Donald S. Davis

Interim Department Head, Delbert M. Gatlin III

December 2006

Major Subject: Wildlife and Fisheries Sciences 


\begin{abstract}
Distribution and Abundance of Endangered Florida Key Deer on Outer Islands.
\end{abstract}

(December 2006)

\author{
Dominique Elijah Watts, B.S., New Mexico State University \\ Chair of Advisory Committee: Dr. Roel R. Lopez
}

Status assessments are compulsory to efficacious management of large-mammal populations, particularly for endangered species such as the Florida Key deer (Odocoileus virginianus clavium). However, a dearth of data regarding basic demographic parameters has limited status assessment and management of Key deer on outer islands. Traditional survey techniques for Key deer on Big Pine and No Name keys include road-counts, strip-counts, and mark-recapture methods. However, practical limitations render traditional survey techniques impractical for application on outer islands. Thus, assessment of current status and appropriate management is limited by a paucity of information regarding Key deer on outer islands. The purpose of my study was to evaluate the utility of infrared-triggered cameras and forward-looking infrared thermography (FLIR) to monitor occupancy and abundance of Key deer on outer islands, and to obtain baseline information regarding current distribution and abundance of Key deer in these areas. In addition, I wanted to further evaluate the advantages and disadvantages inherent in using baited camera-stations to estimate abundance of large mammal populations. I compared 3 frequently applied methods to estimate abundance from camera-based survey data. All outer islands exhibited estimated abundances considerably below carrying capacities, with larger populations occurring closer to Big 
Pine Key. Results indicated that other islands and complexes such as Ramrod Key, Water Key, and the Annette complex maintain only small sub-populations (e.g., $\leq 5$ individuals) and other previously inhabited island complexes (i.e., Johnson complex and Summerland Key) no longer maintain sub-populations. Additionally, I compared abundance estimates from FLIR-based surveys to camera-based estimates. Although no test of accuracy was possible, camera-based survey methods consistently produced higher estimates of Key deer abundance on outer islands. Results indicate that aerial FLIR-based survey methods may be unreliable for the survey of large mammals in tropical habitats or areas exhibiting dense vegetation, and camera-based surveys should be the preferred method to survey Key deer abundance on outer islands. 


\section{DEDICATION}

For my father, mother, and brother. 


\section{ACKNOWLEDGEMENTS}

First, I would like to thank my committee members for their support, friendship, and critical review of my thesis. I would like to thank my committee chair, Dr. Roel R. Lopez, for the opportunity to conduct this research under his supervision and for opportunity to work with a truly unique sub-species. I would also like to acknowledge my committee member, Dr. Nova J. Silvy, for his guidance, encouragement, and enthusiasm. I would also like to thank Dr. Don Davis for his advice and input on this project. Sincere appreciation must also be extended to Dr. Raul Valdez for his guidance and support throughout my academic experience.

I would like to thank Texas A\&M University and the administrative staff at the Department of Wildlife and Fisheries Science, particularly Shirley Konecny, Dawn Miles, and Carol Gaas. Sincere appreciation is extended to Jennifer Baker for getting me out of hot water on more than several occasions. Special thanks go to Dr. Bret Collier for help with Program MARK and writing code for simulations. I would like to extend my sincere appreciation to the Bridge to the Doctorate II Program at Texas A\&M University, the National Science Foundation, and the Houston Safari Club for their financial support and guidance throughout my graduate experience.

I would like to extend my sincere appreciation to the U.S. Fish and Wildlife Service and the National Key Deer Refuge. Particular thanks go to Dr. Phil Frank, Bill Miller, and the staff of the National Key Deer Refuge for their assistance with this project. Additionally, I would also like to thank Florida Keys Mosquito Control for logistics support. 
I would also like to thank my friends and fellow graduate students who made my time in the Florida Keys and College Station a more than memorable experience. Special acknowledgement and appreciation must be given to my friend and colleague Israel D. Parker. Last, but certainly not least, I would like to thank my parents and brother for their love, support, and encouragement. 


\section{TABLE OF CONTENTS}

Page

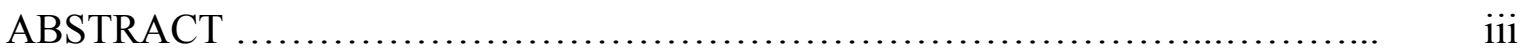

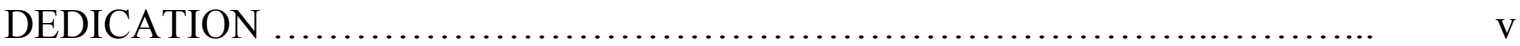

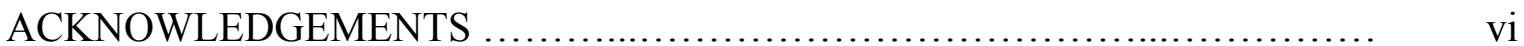

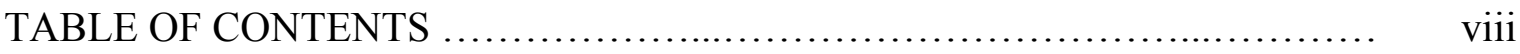

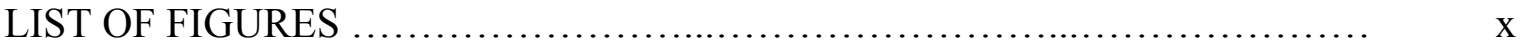

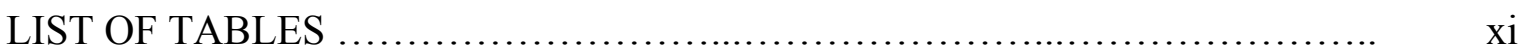

CHAPTER

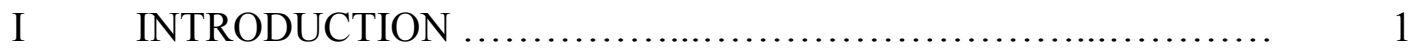

Background ............................................. 1

Research Objectives .................................... 4

II ABUNDANCE AND CURRENT DISTRIBUTION OF ENDANGERED KEY DEER ON OUTER ISLANDS .............. 6

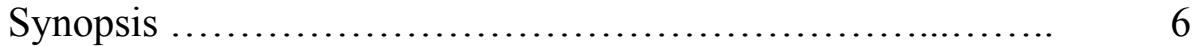

Introduction .............................................. 7

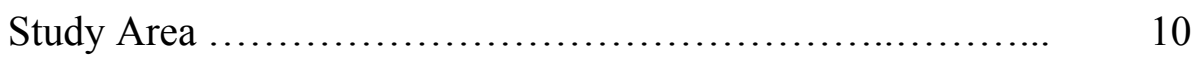

Methods .................................................. 12

Results ................................................ 18

Discussion ................................................. 22

Management Implications .............................. 27

III COMPARISON OF INFRARED-TRIGGERED CAMERAS AND AERIAL THERMAL-IMAGING TO ESTIMATE ABUNDANCE OF ENDANGERED KEY DEER ON OUTER ISLANDS

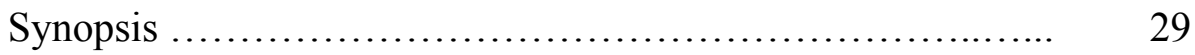

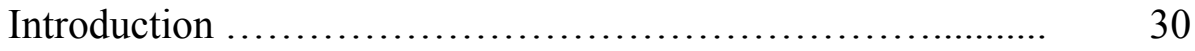

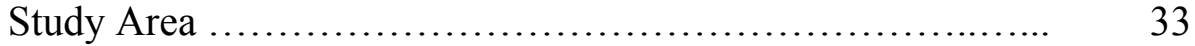

Methods .................................................. $\quad 35$

Results ................................................ 37

Discussion .......................................... 39 
CHAPTER Page

IV CONCLUSIONS AND IMPLICATIONS ....................... 42

Camera-based Surveys ............................... 42

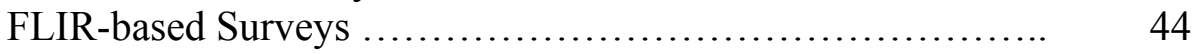

Management Implications ................................ 45

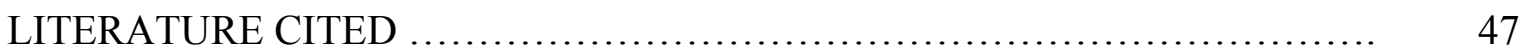

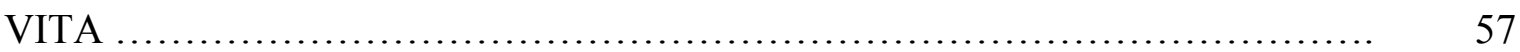




\section{LIST OF FIGURES}

FIGURE

Page

2.1 Map of the Lower Florida Keys, Florida, USA, including all islands within the known distribution of the endangered Florida Key deer .......

2.2 Number of previously unrecorded individually identifiable Key deer (y-axis) captured by day using digital infrared-triggered cameras on outer islands, Lower Florida Keys, Florida, USA, 2005

2.3 Cumulative capture rate for Key deer on all outer islands (excluding Newfound Harbor complex) and Newfound Harbor complex using digital infrared-triggered cameras, Lower Florida Keys, Florida, USA, 2005

3.1 Distribution of the endangered Florida Key deer, Lower Florida Keys, Florida, USA 


\section{LIST OF TABLES}

TABLE Page

2.1 Estimated abundance of Key deer sub-populations on outer islands, Lower Florida Keys, Florida, USA, 2005, derived from digital infrared-triggered camera data

3.1 Comparison of abundance estimates using infrared-triggered cameras and number of Key deer observed using aerial forward-looking infrared-thermography methods, Lower Florida Keys, Florida, USA ... 


\section{CHAPTER I}

\section{INTRODUCTION}

This chapter provides a general outline of my thesis including background information and a breif review of research objectives. My thesis consists of 2 primary chapters (i.e., Chapter II and Chapter III). Each of these chapters represents an independent, but related, research paper and a reasonable amount of repetition should be expected among chapters. Chapter IV provides conclusions and management implications of the research presented in my thesis.

\section{BACKGROUND}

The Florida Key deer (Odocoileus virginianus clavium) was listed as an endangered species by the United States Fish and Wildlife Service (USFWS) in 1967. Key deer are endemic to the Florida Keys, where historic range likely extended from Key Vaca to Key West (Klimstra et al. 1978). Current Key deer distribution is restricted to the Lower Florida Keys, where deer inhabit approximately 20-25 islands from the Johnson keys to Sugarloaf Key. The majority of these islands are contained within the boundaries of the National Key Deer and Great White Heron National Wildlife refuges (Klimstra et al. 1974, Folk 1991, Lopez 2001).

By the late 1940s, habitat loss and unrestricted harvest had reduced the Key deer population to a roughly estimated 25-50 individuals (Dickson 1955). A cartoon drawn by Jay "Ding" Darling in 1934 was instrumental in acquiring national attention and

This thesis follows the format of the Journal of Wildlife Management. 
legislation to protect Key deer. The establishment of the National Key Deer Refuge (1957), curtailment of illegal hunting, and improved habitat conservation on Big Pine and No Name keys allowed the population on these 2 islands to increase to an estimated 300-400 individuals by 1974 (Klimstra et al. 1974). The population continued to increase, growing by approximately 240\% between 1971 and 2001 (Lopez et al. 2004). An estimated $75 \%$ of the current Key deer population resides on Big Pine and No Name keys with the remaining deer distributed throughout the outer islands in small local subpopulations where information regarding Key deer is lacking (Lopez 2001). In my thesis, I refer to all islands within the known distribution of Key deer, excluding Big Pine and No Name keys, as outer islands.

In metapopulation theory, landscapes are viewed as networks of habitat fragments where local sub-populations exist and are connected by dispersal (Levins 1969, Hanski and Simberloff 1997, Meffe and Carroll 1997, Hanski 1998).

Consequently, metapopulation theory is useful when describing Key deer ecology as this subspecies literally occupies a network of oceanic islands linked by dispersal (Lopez 2001). Dispersal is crucial to the stability and persistence of local sub-populations by decreasing extinction risk through re-colonization (Akcakaya 2000). The spatial arrangement and isolation of habitat patches influence despersal rates (Harrison et al. 1988, Kindvall and Ahlén 1992, Hanski et al. 1995, Stith et al. 1996, South 1999). Dispersal rates also are influenced by population density and often exhibit a positive correlation with increasing population density at source populations (Albon et al. 1992). Studies have demonstrated density dependence in white-tailed deer populations 
(McCullough 1979, Halls 1984) and analysis of abomasal parasite counts suggest that Key deer on Big Pine and No Name keys are at or near carrying capacity (Nettles et al. 2002). Thus, outer islands, particularly those close to Big Pine Key, are likely to experience increased immigration. Hanski (1998) concluded that the persistence of metapopulations is influenced by the number of sub-populations present. The size and composition of sub-populaitons also can greatly influence their persistence (May 1973, 1974, Schoener and Spiller 1987, Pimm et al. 1988, Hanski et al. 1994) with smaller sub-populations exhibiting an increased probability of extinction due to factors such as environmental and demographic stochasticity (Caughley 1994). Carrying capacity, habitat characteristics, and juxtaposition in relation to source populations vary considerably among outer islands (Lopez 2001, Harvison et al. 2006). Thus, it is unlikely that the distribution and abundance of Key deer in these areas is spatially or temporally constant, but likely varies with dispersal rates, habitat changes, and the availability of suitable drinking water. Model-based research by Harveson et al. (2006) provides insight into colonization rates on outer islands and Key deer metapopulation dynamics.

Status assessments are compulsory to efficacious management of large mammal populations, particularly for endangered species such as the Florida Key deer. However, a dearth of data regarding basic demographic parameters has limited status assessment and management of Key deer on outer islands. Information regarding the spatial distribution, abundance, and population trends of Key deer on outer islands is necessary for current status assessment and continued management of this endangered species. 
Traditional survey techniques for Key deer on Big Pine and No Name keys include roadcounts, strip-counts, and mark-recapture methods (Silvy 1975, Lopez 2001, Roberts et al. 2006). However, practical limitations (e.g., dense foliage, lack of roads, remote locations, etc.) render traditional survey techniques impractical for application on outer islands. In addition, these methods can be labor-intensive, incur significant financial costs, and may be subject to significant bias (Lancia et al. 1996, Jacobson et al. 1997, Roberts et al. 2006). Application of radio-telemetry methodology (White and Garrott 1990) to estimate Key deer abundance is inhibited by the high cost and effort associated with conducting these methods on outer islands. Other commonly applied methods to estimate abundance of large mammals, such as track and fecal pellet counts (Neff 1968, Fuller 1991), are likely to produce dubious abundance estimates as a result of numerous confounding factors in the study area including low detection probabilities and low deer densities. Thus, assessment of current status and appropriate management of Key deer on outer islands is limited by a paucity of information regarding Key deer in these areas.

\section{RESEARCH OBJECTIVES}

The overall objective of my study was to obtain baseline data regarding the current distribution and abundance of Key deer inhabiting outer islands and to evaluate the efficacy of contemporary survey techniques to obtain this information. My study addressed 2 primary recovery and restoration actions identified in the South Florida Multi-Species Recover Plan (USFWS 1999): 
1. Develop method to survey deer on outer keys where conventional methods (i.e. spotlight counts) are difficult to implement. Obtain current deer density estimates for each island complex (USFWS 1999).

2. Establish a standardized method for future monitoring. Ideally, recommended survey techniques would be easy to apply, cost effective, and detect biologically significant changes in Key deer densities (USFWS 1999).

Data from this study will facilitate appropriate management and conservation of endangered Key deer throughout their range. Additionally, this information will be useful to the USFWS during status assessment and evaluation of the proposed reclassification of Key deer from endangered to threatened. 


\section{CHAPTER II}

\section{ABUNDANCE AND CURRENT DISTRIBUTION OF ENDANGERED KEY DEER ON OUTER ISLANDS}

\section{SYNOPSIS}

Status assessments are compulsory to efficacious management of large mammal populations, particularly for endangered species such as the Florida Key deer. Assessment of current status and appropriate management of Key deer is limited by a paucity of information regarding Key deer on outer islands. Traditional survey techniques for Key deer on Big Pine and No Name keys include road-counts, stripcounts, and mark-recapture methods. However, practical limitations and financial considerations render traditional survey techniques impractical for application on outer islands. Infrared-triggered cameras may provide a practical alternative to estimate Key deer abundance and monitor population trends on these islands. I used digital infraredtriggered cameras to estimate Key deer abundance on 20 outer islands using natural marks (e.g., antler configuration) to identify individual males. These individuals served as a marked subset of the sub-population on their respective islands. I compared 3 frequently applied methods to estimate abundance from camera-based survey data. Abundance estimates for primary natural sub-populations ranged from 15-16 for Howe Key, 5-10 for Knockemdown complex, and 13-17 for Little Pine Key. Differences among abundance estimators became more pronounced for sub-populations such as Newfound Harbor complex (36-150) where model assumptions were violated. Results indicate that other islands and complexes such as Ramrod Key, Water Key, and the 
Annette complex maintain only small sub-populations (e.g., $\leq 5$ individuals) and other previously inhabited island complexes (e.g., Johnson complex and Summerland Key) no longer maintain sub-populations. All outer islands exhibited Key deer abundances well below carrying capacities estimated by Lopez (2001), with larger populations occurring closer to Big Pine Key. Examination of relative abundance among islands raises questions as to the factors which may be limiting Key deer densities in these areas. Although no test of accuracy was possible, camera-based survey methods produced reasonable estimates of Key deer abundance on outer islands when model assumptions were not perceptibly violated. However, sub-population estimates using camera-based survey methods may be subject to inherent biases associated with small sample sizes and behavioral characteristics of individual Key deer. Managers should be cognizant of potential biases and these estimates should be used with prudence in management and status assessment of Key deer.

\section{INTRODUCTION}

The endangered Florida Key deer (Odocoileus virginianus clavium), the smallest subspecies of North American white-tailed deer, is endemic to the Lower Florida Keys (Lopez 2001). Key deer exhibit a restricted distribution within a highly fragmented landscape consisting of 20-25 small oceanic islands. Big Pine Key (2,428 ha) is the largest of the Lower Keys and is the core of the Key deer range (Lopez 2001, Harveson et al. 2006). An estimated $75 \%$ of the total population resides on Big Pine and No Name keys, with the remaining deer inhabiting outer islands which vary considerably in size 
and habitat quality (Lopez 2001). Hereafter, I refer to all islands within the distribution of Key deer, excluding Big Pine and No Name keys, as outer islands.

Information regarding the spatial distribution and population trends of Key deer on outer islands is necessary for status assessment and appropriate management. However, status assessment and appropriate management are currently limited by a paucity of information regarding Key deer abundance and demographic structure on outer islands. Estimation of Key deer abundance on outer islands is challenging due to several confounding factors: (1) Key deer inhabiting outer islands are secretive and difficult to observe; (2) outer islands exhibit dense tropical vegetation that severely limits methods based on direct observation; (3) outer islands lack urban infrastructure (e.g., road systems) and many are completely devoid of roads, being accessible only by boat; (4) collection and analysis of quantitative data is problematic as sub-populations occupying outer islands are small yielding small sample sizes; and, (5) trapping to facilitate traditional mark-resight techniques is likely to be expensive and labor intensive.

Traditional survey techniques for Key deer on Big Pine and No Name keys include road-counts, strip-counts, and mark-recapture methods (Silvy 1975, Lopez 2001, Roberts et al. 2006). However, practical limitations and financial considerations render traditional survey techniques impractical for application on outer islands. Also, Roberts et al. (2006) concluded that traditional techniques (e.g., road counts) used on Big Pine and No Name keys are subject to biases associated with convenience sampling and behavior of Key deer along roadways. Application of radio-telemetry methods to 
estimate abundance of large mammals (White and Garrott 1990) is inhibited by the high cost and effort associated with the application of these methods on outer islands. Other potential estimation techniques for outer islands such as track and fecal pellet counts (Neff 1968, Fuller 1991, Langdon 2001) are likely to produce dubious abundance estimates as a result of numerous confounding factors in the study area including low detection probabilities and low deer densities.

Infrared-triggered cameras may provide a practical and accurate alternative to estimate Key deer abundance and monitor population trends on outer islands. Infraredtriggered cameras have been used widely in wildlife research and management. Camerabased surveys have been used to detect and monitor occupancy of rare mammalian species in remote locations (Bull et al. 1992, Foster and Humphrey 1995, Zielinski and Kucera 1995, Foresman and Pearson 1998), and to estimate abundance of rare or illusive large mammals (Mace et al. 1994, Karanth and Nichols 1998, Sweitzer et al. 2000, Martorello et al. 2003, Silver et al. 2004). Camera-based surveys have also been used to survey large mammals in densely vegetated habitats where visual observation is inadequate to facilitate traditional survey methods (Seydack 1984, Karanth and Nichols 1998, Carbone et al. 2001). The purpose of my study was to evaluate the utility of camera-based surveys to monitor occupancy and abundance of Key deer on outer islands and obtain baseline information regarding the current distribution and abundance of Key deer in these areas. In addition, I wanted to further evaluate the advantages and disadvantages inherent in using baited camera-stations to estimate abundance of large mammal populations (Mace et al. 1994, Jacobson et al. 1997, Koerth et al. 1997). 


\section{STUDY AREA}

The study area is located in the Lower Florida Keys, Monroe County, Florida,

USA. It encompasses all islands within the known distribution of Key deer, the majority of which are contained within the boundaries of the National Key Deer and Great White Heron National Wildlife refuges. Local geology is dominated by 2 Pleistocene formations: Miami limestone (oolite) and older Key Largo limestone below (Hoffmeister and Multer 1968, Halley et al. 1997). Topographic relief is extremely low and most islands are nearly flat with elevations $<2 \mathrm{~m}$. Soils vary from exposed oolitic bedrock to marl deposits and peat (Dickson 1955). Climate is subtropical marine with mean January temperatures of $21^{\circ} \mathrm{C}$, mean July temperatures of $29^{\circ} \mathrm{C}$, and average annual rainfall of $98.8 \mathrm{~cm}$ (National Oceanic and Atmospheric Administration data, 2006). Rainfall is highly seasonal, generally consisting of a 5 month wet season from late May to October, and a long dry season from November through May. Scattered thunderstorms and tropical storms are responsible for wet season precipitation. Island complexes are groups of islands in close proximity to one another separated by shallow waters which can be functionally considered a single island (Folk 1992, Harveson et al. 2006). Klimstra et al. (1974) identified 15 island complexes where Key deer dispersal is relatively unrestricted and observed Key deer or their sign (e.g. tracks, pellets, evidence of browsing) on all 15 complexes. My research occurred on the same 15 island complexes, primarily on the following outer islands and island complexes: Annette complex, Big Torch Key, Cudjoe Key, Howe Key, Johnson complex, Knockemdown complex, Little Pine Key, Little Torch Key, Middle Torch 
Key, Newfound Harbor complex, Ramrod Key, Sugarloaf Key, Summerland Key, and Water Key (Figure 2.1).

Vegetation is principally West Indian in origin (Dickson 1955, Long 1974) and is greatly influenced by elevation (Folk 1991, Lopez 2001). Vegetative communities near sea level are primarily comprised of black mangrove (Avicennia germinans), white mangrove (Laguncularia racemosa), red mangrove (Rhizophora mangle) and other halophytes, which are successively replaced by buttonwood (Conocarpus erectus), hammock, and pineland communities with increasing elevation (Lopez 2001). Outer islands typically exhibit dense tropical vegetation which considerably impedes visibility and movement in these areas. Lopez (2001) reported Key deer on Big Pine Key used upland habitats (i.e., pineland and hammock) and avoided lowland habitats (i.e., buttonwood and tidal areas). However, lowland habitat types occur at comparatively higher proportions on outer islands and Key deer on these islands frequently use buttonwood and seasonally tidal areas (unpublished data). Key deer habitat on outer islands was defined as pineland, hammock, buttonwood forest, seasonally tidal, and developed areas (i.e., all available habitat excluding continually tidal areas). 

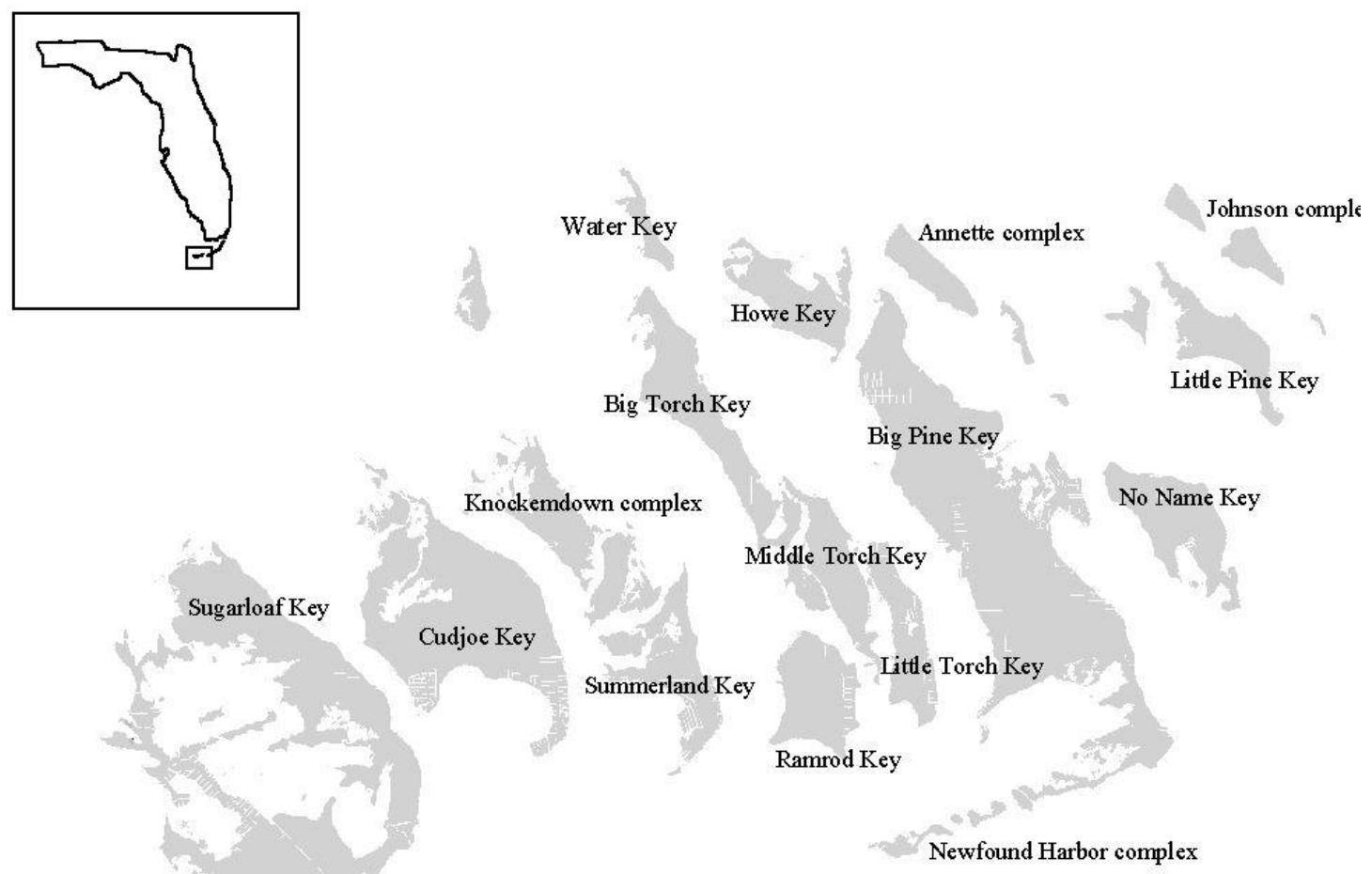

Figure 2.1. Map of the Lower Florida Keys, Florida, USA, including all islands within the known distribution of the endangered Florida Key deer.

\section{METHODS}

\section{Data Collection}

Klimstra et al. (1974) recorded observations of Key deer or their sign on outer islands and this information served as a basis for comparisons of Key deer distribution. Regular exploratory treks were conducted on all outer islands to examine the current distribution of Key deer. Islands were intensively searched for indications of Key deer presence (e.g., tracks, pellets, etc.) and areas of high use (e.g., trails, waterholes, etc.). 
Presence or absence of Key deer sign was recorded for each survey unit to provide distribution data for comparison with historic island occupancy.

Silvy (1975) reported seasonal ranges of Key deer to be 79-275 ha prior to considerable urbanization on Big Pine Key and No Name keys. Lopez (2001) reported significantly smaller seasonal ranges for Key deer (males: 102-309 ha, females: 36-112 ha) and suggested that seasonal ranges of Key deer have decreased as a result of urbanization and domestication on these 2 islands. However, outer islands have undergone comparatively less urbanization, and I suggest that Key deer inhabiting these areas are likely to exhibit seasonal ranges similar to pre-urbanization ranges observed by Silvy (1975).

Total Key deer habitat on island complexes was overlaid with a 50-ha grid to generate $\leq 50$ ha survey units. Camera-stations were placed at a density of 1 camera station per survey unit. Assuming seasonal ranges comparable to those observed by Silvy (1975), camera density provided approximately 1.5-5.5 camera-stations per Key deer home range and offered complete coverage of Key deer habitat on each island complex. A minimum of 2 camera-stations were placed on each complex to account for long narrow islands or complexes consisting of several small islands. Preliminary testing indicated that placement of camera-stations in areas of high use was crucial to acquiring sufficient photographic captures of Key deer. Camera-stations were subjectively placed within sample units at sources of freshwater, along trails, in areas where Key deer or their sign were observed, or along likely travel corridors when no presence was detected. Camera-stations were baited once during setup with $\leq 3.81$ of 
domestic feed (e.g., sweet feed or cracked corn) to entice exploration by Key deer passing in close proximity to the camera-station and maximize photographic captures. Camera-stations were not re-baited and bait was spread sparsely over a large area (50$100 \mathrm{~m}^{2}$ ) around the camera station.

Camera-stations were operated simultaneously on each island complex for 20 consecutive 24-hour periods (days). Commercially available Cuddeback digital infrared-triggered cameras (Non-typical Inc., Park Falls, Wisconsin, USA) were used to photograph Key deer. This system is a self-contained digital camera utilizing a passive infrared sensor. Cameras were mounted on vegetation or constructed platforms approximately $30 \mathrm{~cm}$ above ground and set to manufacturer-recommended settings for local environmental conditions. Picture delay was set to 1 minute and video mode was used to record 10-20 seconds of video after the initial photograph. Video was used to increase accuracy during identification of individuals and to document neonates which might not be recorded in initial photographs. Date and time were automatically recorded on each digital photograph.

\section{Data Analysis}

Digital photographs were scrutinized to identify individual Key deer by antler configuration. Preliminary data indicated that marked individuals lingered at recently baited camera-stations a maximum of 47 minutes. Multiple photographs of indistinguishable deer within a $\leq 1$-hour period at a single camera-station were excluded during analysis to minimize double-counting animals. Thus, valid photographic captures were identified and individually identifiable adult male Key deer served as marked 
individuals. Photographic captures were grouped into 4 categories (Jacobson et al. 1997): (1) individually identifiable adult males, (2) adult females, (3) indistinguishable antlered males (e.g., spikes), and (4) sub-adults. Valid captures were calculated separately for each camera-station and pooled for each island complex. In addition to adult males, collared females from a concurrent study on Cudjoe and Sugarloaf keys served as marked females for analysis of sightability. However, collared females were treated as un-marked adult females during calculation of sub-population abundance.

Using the same 20-day survey data, 3 frequently used methods to calculate abundance from camera surveys were compared. Methods described by Jacobson et al. (1997) were used to calculate abundance estimates for a 20-day survey period. A 2sample Peterson model (Seber 1982) was used to calculate a second abundance estimate using a 10-day mark and 10-day re-sight period. Baily's binomial model (Bailey 1952) was used as it is more robust to small sample sizes (Seber 1982). Resultant abundance estimates were then fit to a Poisson distribution and simulations were used to develop corrected population estimates using sightability of known deer on Cudjoe and Sugarloaf keys (70-100\%). Finally, a third abundance estimate was obtained using methods developed by Minta and Mangel (1989) which uses the capture frequencies of marked individuals to estimate capture frequencies of non-marked individuals by means of bootstrap methods. Minta-Mangel estimates were calculated using Program NOREMARK (White 1996). Lower bounds of confidence intervals were adjusted to account for the minimum number known alive on each island complex where applicable, and all fractions were rounded up to the nearest whole number. 
Total sampling effort was defined as the sum of all 24-hour periods (days) cameras were operated on an island complex. Photographic capture rate was defined as the number of valid photographic captures of Key deer per day summed for all camera stations on an island complex. Catch per unit effort (CPUE) was defined as $\mathrm{C} / \mathrm{X}$, where $\mathrm{C}$ is the total valid photographic captures and $\mathrm{X}$ is the total sampling effort for each island complex.

\section{Model Assumptions}

Methods developed by Jacobson et al. (1997) are solely designed to estimate population size and rely heavily on closure assumptions. The Peterson model also relies heavily on assumptions of geographic and demographic closure. Using methods presented here it is difficult to formally address closure assumptions. However, geographic closure can reasonably be assumed as individual islands represent functionally closed island populations during the survey period and entire island complexes were sampled simultaneously. The short duration of the total survey (i.e., 20 days) reasonably satisfies demographic closure assumptions and also allows the assumption of mark retention for the entirety of the survey. The use of cameras also allows assumption of little or no disturbance to natural activities which are commonly associated with live-capture studies. When estimating the density of animals in an area, studies typically add a boundary strip to the area defined by grids in order to account for captured animals that commonly occur outside the grid area (Otis et al. 1978, White et al. 1982). However, this method was not applied as I assume complete camera coverage of Key deer habitat on each island complex. 
Sightability in any sample is a function of an individual animal and varies over the population according to sex, age, and other factors (Pollock 1982, White et al. 1982). Model assumptions such as equal sightability among all individuals, independence of sightings, and population closure are rarely met in toto (Arnason et al. 1991) and studies using photographs to obtain information regarding abundance commonly assume equal detectability among individuals (Cutler and Swann 1999). Baiting may introduce bias which affects the accuracy and precision of abundance estimates (White et al. 1982). Cumulative photographic capture rate was examined to test for bait induced bias.

It is impossible to test the assumption of equal sightability among survey periods using a 2-sample Peterson model with any statistical power (Krebs 1999). Sighting histories were developed for all individually identifiable Key deer on outer islands using each day as a sampling period $(n=20)$. The assumption of equal sightability of Key deer by day was tested using a Zero-Truncated Poisson Test for Equal Sightability (Caughley 1977). Expected values were derived from observed data and expected values $<1.0$ were amalgamated into a single category (i.e., $\geq 9$ captures). A Chi-square goodness-of-fit test was conducted on these data to test the null hypothesis of equal sightability among Key deer by day. To evaluate sightability among sexes and the validity of using only males as marked individuals on outer islands, capture histories for individually identifiable males on all outer islands and collared females on Cudjoe and Sugarloaf keys were analyzed using Program MARK (White and Burnham 1999).

One method to improve the accuracy of abundance estimates is to replicate surveys (White and Garrott 1990). Practical limitations, the need to obtain baseline data 
for all outer islands within the alloted timeframe of the study, and setbacks due to hurricanes prohibited replication of surveys on individual islands. However, 2 surveys were conducted on Sugarloaf Key to gain insight into the precision of camera-based estimates of Key deer abundance.

\section{RESULTS}

Key deer or their sign were detected on 13 of 15 historically occupied island complexes. In addition, Key deer presence was documented on Spanish Harbor Key. No evidence of Key deer presence was detected on Summerland Key or Big Johnson complex. Results of camera-based island occupancy surveys were equivalent to sign surveys used by Klimstra et al. (1974). Additionally, cameras detected Key deer presence in 2 survey units where sign surveys did not produce indications of presence.

Cameras obtained 649 valid photographic captures of Key deer on outer islands. Sixteen of $19(84.2 \%)$ known individually identifiable Key deer inhabiting outer islands were photographically captured by Day 10. Seventy percent of known Key deer on Sugarloaf and $100 \%$ of known deer on Cudjoe were photographically captured by Day

10. Cumulative capture rate for new individually identifiable Key deer reached asymptote around Day 9 and only 2 previously unidentified Key deer were captured after day 10 (Fig. 2.2). One of 2 new marked deer appearing after Day 10 was likely to have immigrated from south Big Pine Key to Newfound Harbor complex. Individually identifiable ('marked') Key deer were regularly captured throughout the 20-day survey period at multiple camera stations. Mean capture of 'marked' individuals during re- 
capture sessions was 2.7 and 2.4 for males and females respectively. Number of recaptures for individual 'marked' Key deer ranged from 1-7. Results of Zero-Truncated Poisson Tests of Equal Sightability indicated that sightability by day was not equal among all individual marked Key deer $(P<0.001)$. Results of model selection using Program MARK indicated no significant difference in sighting probabilities by day between sexes $($ male $=0.244, \mathrm{SE}=0.031$; female $=0.224, \mathrm{SE}=0.019)$.

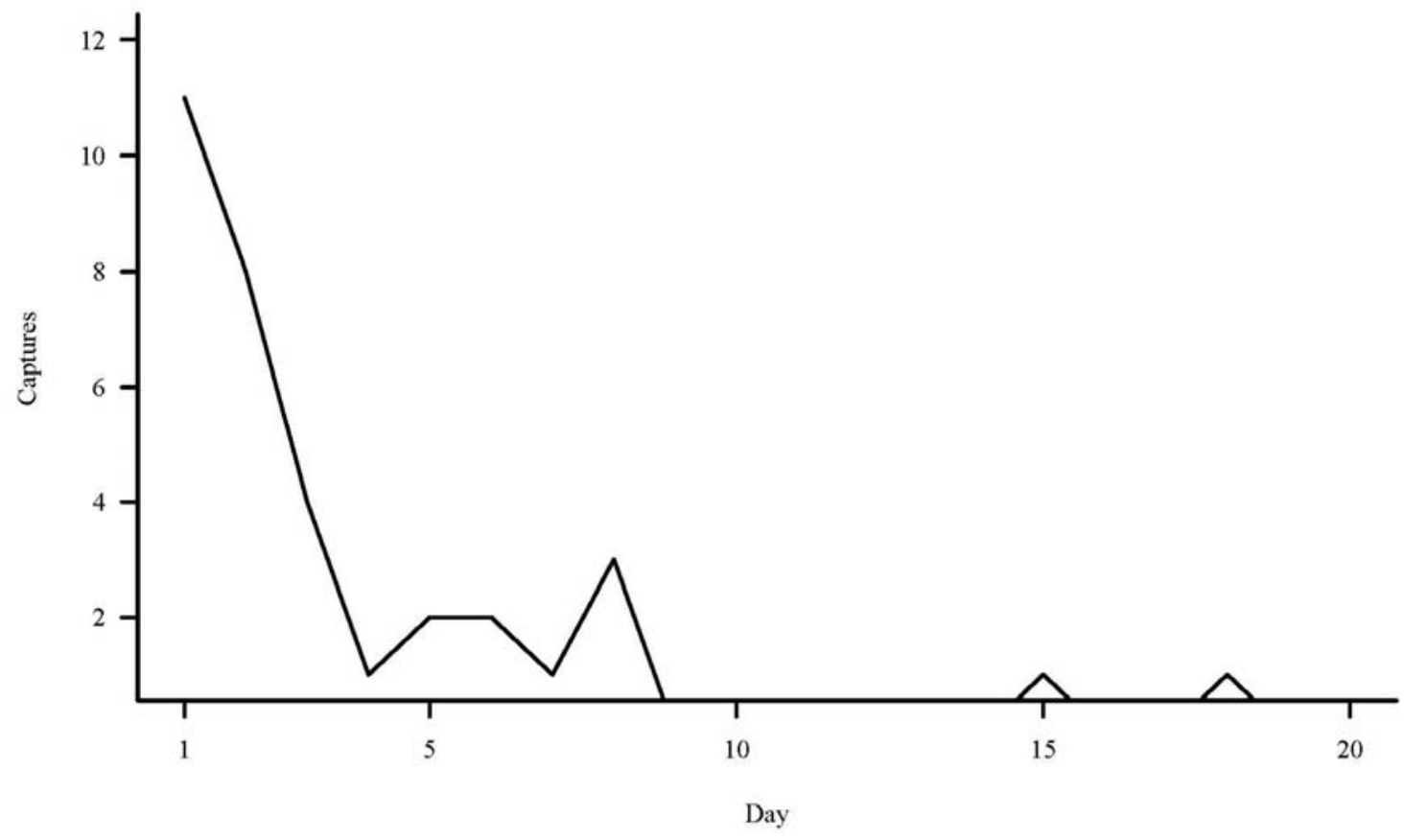

Figure 2.2. Number of previously unrecorded individually identifiable Key deer (yaxis) captured by day using digital infrared-triggered cameras on outer islands, Lower Florida Keys, Florida, USA, 2005. 
Estimated abundance and density of Key deer varied considerably among outer islands (Table 2.1). Absence of mature males on several islands prohibited calculation of abundance. For these island complexes, the minimum number known alive should be considered a conservative sub-population estimate and these sub-populations are assumed to consist of $\leq 5$ individuals. The Peterson estimator produced negatively biased pre-adjustment estimates (i.e., below MNKA) on Cudjoe Key due to 'trap-happy' male Key deer. Conversely, estimators may have over-estimated abundance on Newfound Harbor complex. Bias was likely due to violations of closure assumptions, 'trap-shy' marked individuals during re-capture sessions, an unusually high density of Key deer due to proximity to Big Pine Key, and anthropogenic factors described in more detail below.

Cumulative capture rate indicated baiting had a considerable effect on the number of photographic captures of Key deer (Fig. 2.3). Photographic captures were highest during the first 2-4 days of each survey and declined considerably until becoming more stable around 5-6 days. Newfound Harbor complex was excluded from cumulative results for several reasons: (1) Newfound Harbor complex is a primary dispersal area for south Big Pine Key, (2) Newfound Harbor has an unusually high density of Key deer due to anthropomorphic factors (e.g. camp grounds, ornamental plants), and (3) Newfound Harbor is used as a corridor to Little Palm Island where Key deer feed on ornamental plants, utilize freshwater resources, and are regularly fed by island occupants. 
Table 2.1. Estimated abundance of Key deer sub-populations on outer islands, Lower

Florida Keys, Florida, USA, 2005, derived from digital infrared-triggered camera data.

\begin{tabular}{lrrrrrr}
\hline Island complex & $\begin{array}{c}\text { Area } \\
\text { (ha) }\end{array}$ & $\begin{array}{c}\text { Jacobson } \\
\text { estimate }\end{array}$ & $\begin{array}{c}\text { Peterson } \\
\text { estimate } \\
\text { (adjusted) }\end{array}$ & $\begin{array}{c}\text { Minta- } \\
\text { Mangal } \\
\text { estimate }\end{array}$ & MNKA $^{\mathrm{a}}$ & CPUE $^{\mathrm{b}}$ \\
\hline Annette complex & 222 & $\mathrm{NC}^{\mathrm{c}}$ & $\mathrm{NC}^{\mathrm{c}}$ & $\mathrm{NC}^{\mathrm{c}}$ & 1 & 0.05 \\
Cudjoe & 1,319 & 9 & 8 & 11 & 7 & 0.99 \\
Howe & 373 & 15 & 16 & 16 & 9 & 1.80 \\
Johnson complex & 154 & 0 & 0 & 0 & 0 & 0.00 \\
Knockemdown complex & 582 & 5 & 9 & 10 & 3 & 0.27 \\
Little Pine & 381 & 17 & 12 & 13 & 4 & 0.67 \\
Newfound Harbor complex & 76 & 36 & 93 & 150 & 6 & 4.15 \\
Ramrod & 374 & $\mathrm{NC}$ & $\mathrm{NC}$ & $\mathrm{NC}^{\mathrm{c}}$ & 1 & 0.35 \\
Sugarloaf (survey 1) & 1,399 & 27 & 22 & 69 & 5 & 0.59 \\
Sugarloaf (survey 2) & 1,399 & 23 & 30 & 25 & 5 & 0.64 \\
Summerland & 436 & 0 & 0 & 0 & 0 & 0.00 \\
Big Torch & 626 & 17 & 29 & $\mathrm{NC}^{\mathrm{c}}$ & 4 & 0.17 \\
Little Torch & 305 & 8 & 5 & $\mathrm{NC}^{\mathrm{a}}$ & 3 & 0.20 \\
Middle Torch & 410 & 3 & 4 & 3 & 3 & 0.05 \\
Water & 92 & $\mathrm{NC}$ & $\mathrm{NC}^{\mathrm{c}}$ & $\mathrm{NC}^{\mathrm{c}}$ & 1 & 0.10 \\
\hline
\end{tabular}

${ }^{a}$ MNKA, absolute minimum number of individual Key known to be alive during survey.

${ }^{\mathrm{b}}$ CPUE (catch per unit effort), defined as the total number of valid photographic captures divided by the total number of camera days (i.e., number of cameras multiplied by 20 days).

${ }^{\mathrm{c}} \mathrm{NC}$, estimate was not calculable due to insufficient captures of individually identifiable Key deer during capture or re-capture periods. 


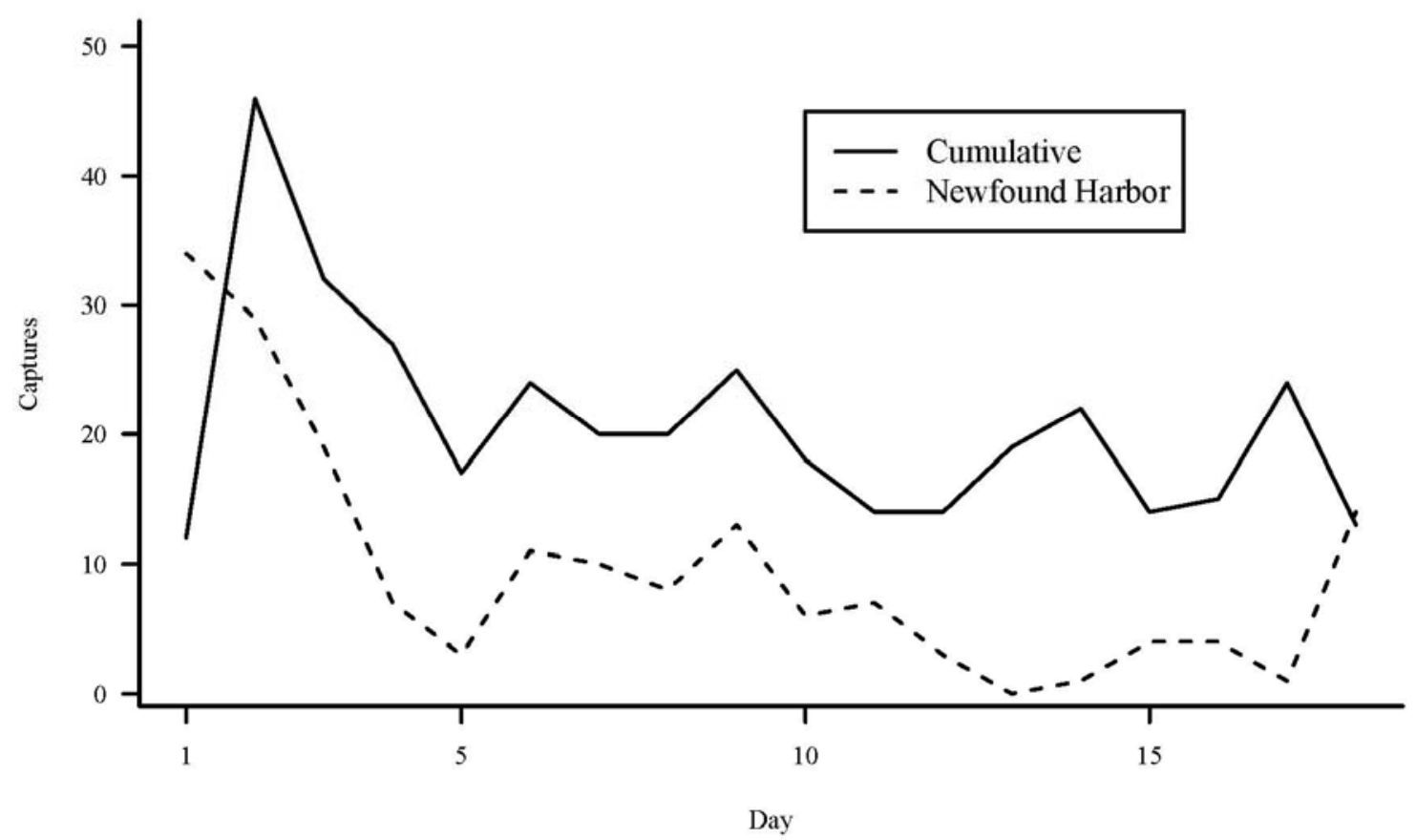

Figure 2.3. Cumulative capture rate for Key deer on all outer islands (excluding Newfound Harbor complex) and Newfound Harbor complex using digital infraredtriggered cameras, Lower Florida Keys, Florida, USA, 2005.

\section{DISCUSSION}

Jacobson et al. (1997) reported $100 \%$ and $88 \%$ of known deer were photographically captured during a 14 -day period and $100 \%$ and $82.3 \%$ where captured during the first 10 days of the survey. Similar results during this study ( $84.2 \%$ by Day 10), observed cumulative photographic capture rate of new individuals, and photographic captures of marked deer at multiple camera stations indicate that the majority of Key deer inhabiting outer islands were recurrently photographically 
captured. Thus, camera density on islands appears to have been sufficient. Higher camera density might result in capture of all individuals but may not be practical. Data analysis also indicated closure assumptions were reasonably met. Misidentification of individuals during analysis, particularly marked individuals, could potentially bias survey results. However, marked individuals in this study offered distinctly recognizable characteristics which permitted accurate identification during analysis.

Karanth (1995), Jacobson et al. (1997) and Koerth (1997) noted that heterogeneous sightability of different age and sex classes could bias abundance estimates based on photographic data. Tests of equal sightability by survey period (i.e. 10 days) could not be conducted with any statistical power. However, results of ZeroTruncated Poisson Test of Equal Sightability indicated that sightability of Key deer by day was heterogeneous among individuals. Although it is difficult to relate sightability by day to sightability by survey period (10 days), these results indicate model assumptions of homogeneous sightability among individuals may have been violated. However, the mean number of captures during re-capture sessions (males: 2.7, females: 2.4) and results of model selection using Program MARK indicate sightability of Key deer is not a function of sex. Equivalent detection probabilities between sexes indicated the use of male Key deer as marked individuals in sub-populations is permissible, thus, minimizing the need for expensive and labor intensive capture operations.

Baiting offered advantages and disadvantages to camera-based surveys and the effects of baiting should be thoroughly examined prior to implementation of camerabased surveys. Jacobson et al. (1997) and Koerth et al. (1997) used bait at camera 
stations to increase photographic captures of white-tailed deer. However, the Jacobson estimator relies heavily on assumptions of equal sightability among all individuals throughout the survey period (e.g., 20 days in this study). A decline in cumulative capture rate indicated baiting affected sightability of Key deer through the survey period. Bias associated with heterogeneous sightability among all individuals is likely to be exacerbated as "trap-happy" individuals could significantly influence results if camera stations are regularly baited. Thus, baiting should not be employed when collecting data for use with methods described by Jacobson et al. (1997). Another possible method to minimize the effects of baiting using the Jacobson estimator would be to exclude the period where influence of bait was most significant (e.g., Days 1-5 in this study). Conversely, the 2-sample Peterson model is not affected by differential sightability between marking and re-sighting sessions provided that sightability is homogeneous within the re-sight session and observation in the first session is independent of observation in the second. Cumulative capture rates indicated the effects of baiting Key deer dissipated by Day 5 allowing increased captures during 'marking' periods (i.e., increased marked individuals) without violating model assumptions.

Three frequently applied methods to estimate abundance from camera-based survey data were compared in this study. All 3 estimators produced reasonable results (i.e., compared to sign observed) when model assumptions were not perceptively violated. However, abundance estimators produced spurious results for sub-populations where assumptions of homogeneous sightability were violated. Islands such as Newfound Harbor complex were likely biased high due to low sightability of 'marked' 
Key deer during re-capture sessions and violations of closure assumptions. Conversely, on Cudjoe Key, 2 males were captured on as many as 5-7 occasions during the 10-day recapture session whereas other 'marked' Key deer were typically captured on 2-3 occasions during this same time period. Thus, estimates of abundance on Cudjoe Key would be expected to be negatively biased. All 3 estimators used to develop abundance estimates are subject to inherent biases associated with small samples sizes and sightability of individual deer. Sightability of individual Key deer is an inherent problem when estimating Key deer abundance using camera-based methods. Methods developed by Minta and Mangel (1989) address variation in sightability among individual Key deer and I recommend application of this method when estimating abundance of Key deer on outer islands.

This study provides current information regarding the distribution and status of Key deer inhabiting these areas. Data indicate the distribution of Key deer may have constricted since the early 1970s. Absence of Key deer on previously occupied islands such as Big Johnson and Summerland keys may be an indication of declines on outer islands. Big Johnson likely serves as a sink or dispersal area for the sub-population on Little Pine Key. Thus, the current absence of Key deer on Big Johnson Key is indicative of sub-population declines on Little Pine Key and the same holds true for source populations near Summerland and Ramrod keys. However, meta-populations are dynamic and the absence or low density of Key deer on specific outer islands may be the result of natural fluctuation in meta-population structure. 
This study is the first effort to estimate abundance of Key deer sub-populations on outer islands. Model-based research by Harveson et al. (2006) concluded that distance from source populations and island size significantly effects Key deer abundance on outer islands, and the results of this study support their conclusions. Natural (i.e., excluding translocations) Key deer abundance was greatest on island complexes closest to Big Pine Key (e.g., Howe Key, Little Pine Key, and Big Torch). Estimates for other island complexes such as Ramrod Key, Water Key, and Annette complex indicate that these islands maintain only small sub-populations (i.e., $\leq 5$ individuals) which are likely seasonal or ephemeral in nature. All outer islands, with the exception on Newfound Harbor complex, exhibited Key deer abundances well below carrying capacities estimated by Lopez (2001). The effects of recent hurricanes on vegetation and freshwater quality are possible explanations for the observed constriction of distribution and low abundances. Examination of relative abundance among outer islands raises questions as to the factors which may be limiting Key deer abundance in these areas. Islands such as Sugarloaf and Cudjoe have sufficient habitat and would be expected to maintain higher Key deer densities than were observed. It is important to note that estimates presented here include translocated Key deer on Cudjoe and Sugarloaf and natural Key deer numbers were likely low ( $\leq 5-10$ individuals) prior to translocations. It is likely that Key deer naturally occur at densities below carrying capacity on outer islands and the high densities observed on Big Pine and No Name keys are the product of anthropogenic influence. However, primary factors effecting the 
distribution and abundance of Key deer throughout their range (e.g., fresh water) warrant further investigation.

\section{MANAGEMENT IMPLICATIONS}

Reclassification of Key deer from endangered to threatened has recently been proposed as a result of increased Key deer densities at the core of their range (i.e., Big Pine and No Name keys; Lopez et al. 2004). Attempts to establish viable subpopulations (Parker 2006) address other recovery criteria regarding increased Key deer abundance on outer islands. Other recovery criteria such as evaluation of status and trends of Key deer on islands will also play an important role in the decision making process. Information from this study will be useful during evaluation of the proposed reclassification of Key deer. Data from this study also will facilitate appropriate management and conservation of the endangered Key deer throughout their range.

A primary concern of wildlife managers is the costs associated with the monitoring of wildlife populations. Use of natural markings is preferred to activemarking techniques for Key deer due to the temporal and financial costs associated with maintaining marked segments of sub-populations on 20-25 outer islands. Similar sightability among male and female Key deer and use of natural marks minimized temporal and financial costs associated with conducting surveys of abundance on outer islands. In addition, this method alleviates the need to capture and mark Key deer.

Use of digital infrared-triggered camera equipment offered several advantages over traditional film-operated systems. Roberts et al. (2006) reported that film-operated 
camera surveys cost approximately $\$ 85$ per week (11 cameras) excluding vehicle, fuel, and camera equipment. Comparatively, cost associated with operation of 11 digital cameras for up to 30 days is approximately $\$ 55$ excluding boat, fuel, and equipment. Digital cameras also minimize disturbance to study subjects and significantly reduce trips in the field by requiring significantly less maintenance (e.g. changing film). This may be a significant advantage for diffident species such as large felids. In addition, digital systems can minimize data loss associated with loss of available film caused by non-target species as reported by Karanth (1995), Koerth et al. (1997), and Kawanishi (2002).

Digital camera-based surveys offer an accurate and practical method to monitor island and habitat occupancy, offering insight into the status and trends of Key deer throughout their range. Results indicate camera-based surveys may provide a practical method to monitor Key deer abundance and population trends on outer islands. In addition, camera-based surveys could provide a method to evaluate the efficacy of management actions on outer islands such as translocations and habitat manipulation. However, sub-population estimates may be subject to inherent bias associated with small sample sizes and behavioral characteristics of individual Key deer. Differences between the 2 surveys conducted on Sugarloaf Key suggest it may be advantageous to conduct multiple surveys to address the precision of abundance estimates. Managers should be cognizant of potential biases and sub-population estimates should be used with prudence in management of Key deer. Further validation of camera-based surveys is desirable. 


\section{CHAPTER III}

\section{COMPARISON OF INFRARED-TRIGGERED CAMERAS AND AERIAL THERMAL-IMAGING TO ESTIMATE ABUNDANCE OF ENDANGERED KEY DEER ON OUTER ISLANDS}

\section{SYNOPSIS}

Status assessments are compulsory to efficacious management of large mammal populations, particularly for endangered species such as the Florida Key deer. Assessment of current status and appropriate management of Key deer is limited by a paucity of information regarding Key deer on outer islands. Traditional survey techniques for Key deer include road-counts, strip-counts, and mark-recapture methods. However, practical limitations and financial considerations render traditional survey techniques impractical for application on outer islands. I compared surveys using forward looking infrared-thermography (FLIR) technology and digital infrared-triggered cameras to estimate Key deer abundance on outer islands. Utility of aerial FLIR-based surveys appears to be limited by low sightability due to dense tropical vegetation. Although no test of accuracy was possible, camera-based survey methods consistently produced higher estimates of Key deer abundance on outer islands. However, subpopulation estimates using camera-based survey methods may be subject to biases associated with small sample sizes and behavioral characteristics of individual Key deer. Managers should be cognizant of potential biases inherent in methods to estimate abundance of Key deer on outer islands and these estimates should be used with prudence in management of this endangered species. 


\section{INTRODUCTION}

The endangered Florida Key deer (Odocoileus virginianus clavium), the smallest subspecies of North American white-tailed deer, is endemic to the Lower Florida Keys. Key deer exhibit a restricted distribution within a highly fragmented landscape consisting of 20-25 small oceanic islands. Big Pine Key $(2,428$ ha) is the largest of the Lower Keys and is the core of the Key deer distribution (Lopez 2001, Harveson et al. 2006). Approximately $75 \%$ of the total population resides on Big Pine and No Name keys, with the remaining deer inhabiting outer islands which vary considerably in size and habitat characteristics (Lopez 2001). Here, I will refer to all islands within the Key deer range, excluding Big Pine and No Name keys, as outer islands. Information regarding the spatial distribution and population trends of Key deer on outer islands is necessary for status assessment and appropriate management. However, status assessment and appropriate management are currently limited by a paucity of information regarding Key deer on outer islands.

Traditional survey techniques for Key deer on Big Pine and No Name keys include road counts, strip counts, and mark-recapture methods (Silvy 1975, Lopez 2001, Roberts 2006). Practical limitations and financial considerations render traditional survey techniques impractical for application on outer islands. Additionally, Roberts et al. (2006) concluded that traditional survey methods are subject to bias derived from convenience sampling. Application of radio-telemetry methods to estimate Key deer abundance (Silvy 1975, Lopez 2001) is inhibited by the high cost and effort associated with conducting these methods on outer islands. Other potential estimation techniques 
for outer islands, such as track and fecal pellet counts (Neff 1968, Fuller 1991, Langdon 2001), are likely to produce dubious abundance estimates as a result of numerous confounding factors in the study area including low detection probabilities and low deer densities. Infrared-triggered cameras have been used widely in wildlife research and management and may provide a practical method to monitor Key deer on outer islands. Accuracy of camera-based surveys may be subject to bias associated with small sample sizes and heterogeneous sightability among individual Key deer. In addition, camerabased surveys require approximately 21-30 days to complete per island complex and it may not be practical to survey all outer islands annually.

Forward-looking infrared thermography (FLIR) detects thermal radiation from objects and converts this radiation into visible images allowing differentiation between objects of different temperatures. Thus, FLIR technology can be used to detect the presence of large mammals which emit thermal radiation at higher intensity that background objects. Boonstra et al. (1994) gives a more detailed description of FLIR technology. Forward looking infrared-thermography technology has been used to survey large mammal populations (Croon et al. 1968, Havens and Sharp 1998, Wiggers and Beckerman 1993, Dunn et al. 2002) and may provide a practical and accurate alternative to estimate Key deer abundance and monitor population trends on outer islands. Primary sub-populations occur on Big Torch, Cudjoe, Howe, Little Pine, Big Knockemdown, Little Knockemdown, and Sugarloaf keys. However, many outer islands exhibit small Key deer sub-populations (e.g., $\leq 5$ individuals) which are difficult to accurately estimate using camera-based surveys. FLIR-based surveys may provide an alternative method to 
survey these small sub-populations accurately. Aerial FLIR-based surveys also could provide a temporally effective method to obtain sub-population estimates offering managers the ability to annually survey all outer islands and make status assessments immediately following natural disasters such as major hurricanes or disease outbreaks.

Limitations and local conditions may restrict the utility of FLIR for the survey of large mammals in tropical and sub-tropical conditions. Wyatt et al. (1980) indicated that surveys using thermal contrast alone may be insufficient for the survey of large mammals. Inadequate differences between ambient and biological temperatures can significantly limit aerial detection of large mammals using FLIR technology. Exposed ground and rocks, and thermal radiation from vegetation also may cause false detections and this problem may be exacerbated in warmer climates such as the tropics.

Additionally, dense vegetation may limit the utility of FLIR technology for the survey of large mammals (Garner et al. 1995, Dunn et al. 2002), particularly in tropical and subtropical environments where dense vegetation is generally pervasive. FLIR technology has been most successfully applied in open vegetation types or controlled environments (Croon et al. 1968, Wiggers and Beckerman 1993, Naugle et al. 1996). Havens and Sharp (1998) reported positive results using FLIR to survey large mammal populations in wooded areas in southern Florida, USA. This study suggests FLIR-based surveys might provide a functional method to survey Key deer. The purpose of this study was to compare camera-based and FLIR-based methods to survey Key deer sub-populations on outer islands and further investigate the utility of FLIR in sub-tropical environments. 


\section{STUDY AREA}

The study area is located in the Lower Florida Keys, Monroe County, Florida, USA. It encompasses all islands within the known distribution of Key deer (Figure 3.1), the majority of which are contained within the boundaries of the National Key Deer and Great White Heron National Wildlife refuges. Local geology is dominated by 2 Pleistocene formations: Miami limestone (oolite) and older Key Largo limestone below (Hoffmeister and Multer 1968, Halley et al. 1997). Topographic relief is extremely low and most islands are nearly flat with elevations $<2 \mathrm{~m}$. Soils vary from exposed oolitic bedrock to marl deposits and peat (Dickson 1955). Climate is subtropical marine with mean January temperatures of $21^{\circ} \mathrm{C}$, mean July temperatures of $29^{\circ} \mathrm{C}$, and average annual rainfall of $98.8 \mathrm{~cm}$ (National Oceanic and Atmospheric Administration data, 2006). Rainfall is highly seasonal, generally consisting of a five month wet season from late May to October, and a long dry season from November through May. Scattered thunderstorms and tropical storms are responsible for wet season precipitation.

Vegetation is principally West Indian in origin (Dickson 1955, Long 1974) and is greatly influenced by elevation (Folk 1991, Lopez 2001). Vegetative communities near sea level are primarily comprised of black mangrove (Avicennia germinans), white mangrove (Laguncularia racemosa), red mangrove (Rhizophora mangle) and other halophytes, which are successively replaced by buttonwood (Conocarpus erectus), hammock, and pineland communities with increasing elevation (Lopez 2001). Outer islands typically exhibit dense tropical vegetation that considerably limits visibility and the applicability of traditional methods to survey large mammals (Lancia et al. 1996, 
Jacobson et al. 1997, Jachmann 2002). Vegetation density is decreased in February during leaf-off offering a period of increased visibility for aerial surveys. Lopez (2001) reported Key deer on Big Pine Key used upland habitats (i.e., pineland and hammock) and avoided lowland habitats (i.e., buttonwood and tidal areas). However, lowland habitat types occur at comparatively higher proportions on outer islands and Key deer on these islands frequently use buttonwood and seasonally tidal areas (unpublished data). Key deer habitat on outer islands was defined as pineland, hammock, buttonwood forest, seasonally tidal, and developed areas (i.e., all available habitat excluding continually tidal areas).
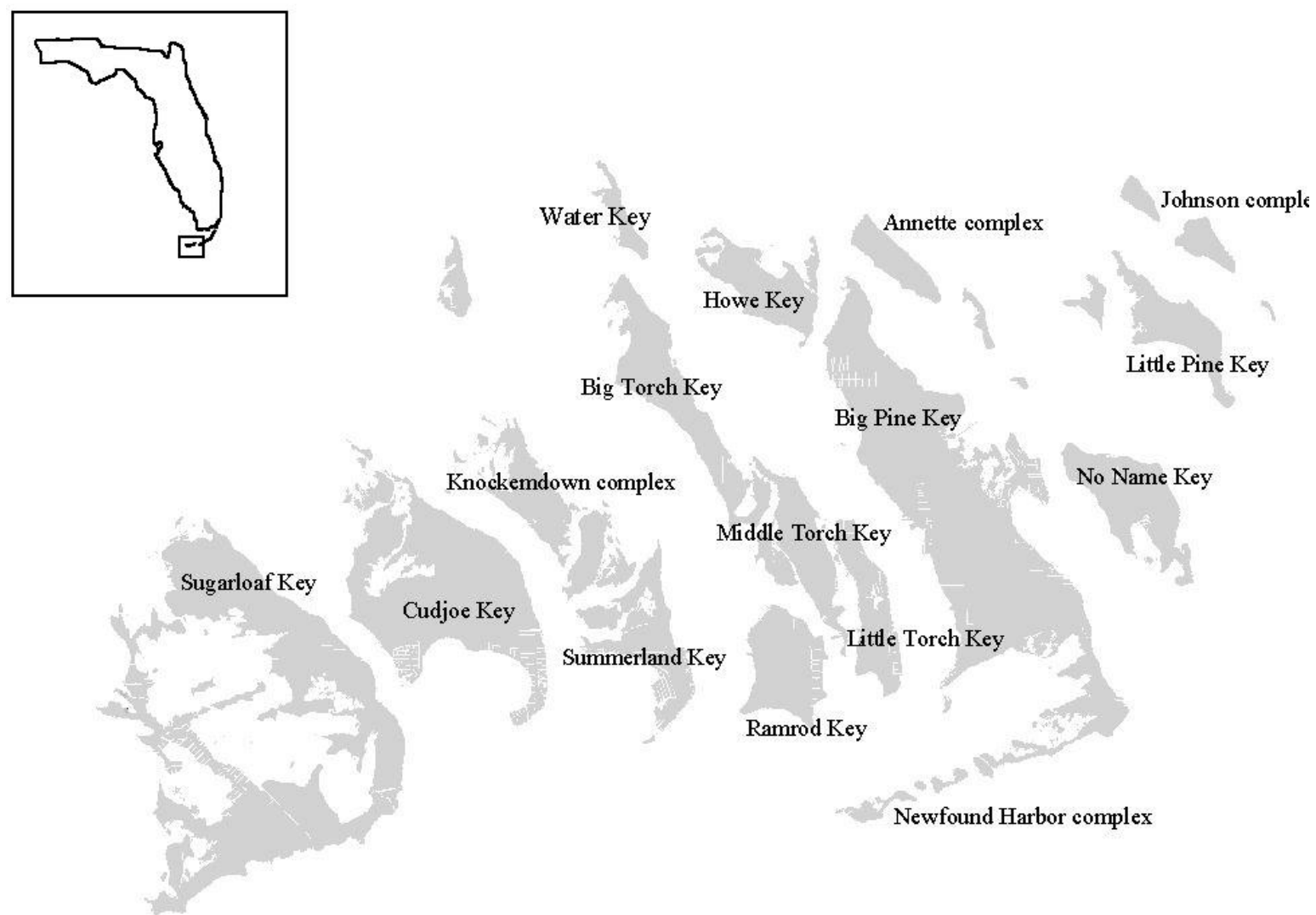

Figure 3.1. Distribution of the endangered Florida Key deer, Lower Florida Keys, Florida, USA. 


\section{METHODS}

\section{Aerial-FLIR Surveys}

Aerial-FLIR surveys were conducted on from a Bell Ranger 206L-4 helicopter using a handheld ThermaCAM ${ }^{\circledR}$ B-20 (FLIR Systems, North Billerica, Massachusetts, USA) with a $24^{\circ}$ lens. At least one survey was conducted on Annette complex, Cudjoe Key, Howe Key, Knockemdown complex, Little Pine Key, Knockemdown, Sugarloaf Key, Torch complex, and Water Key. Surveys were conducted during early morning to maximize thermal contrast between Key deer and background (Havens and Sharp 1998). Flights were conducted at an altitude of $90-100 \mathrm{~m}$ as preliminary tests indicated this elevation offered optimal FLIR ground-swath width without flushing Key deer and double counting (Naugle et al. 1996). The ThermaCAM ${ }^{\circledR}$ FLIR system provided a $24^{\circ} \mathrm{x}$ $18^{\circ}$ field of view resulting in a ground swath approximately $28-\mathrm{m}$ wide (vertical swath varied with camera pitch). North-south transects were flown at approximately 16-24 $\mathrm{km} /$ hour (9-13 knots) and transects offered complete coverage of islands. The FLIR unit was operated by an experienced observer during all preliminary testing and surveys. Observer door was removed and panning technique was employed to improve detection of deer in wooded areas and discrimination of large mammal species (Havens and Sharp 1998). Number and location of Key deer thermal signatures were recorded by a second observer in the helicopter. FLIR-based population estimates represent minimum counts of Key deer on their respective islands. 


\section{Camera-based Surveys}

Island complexes were divided into 50-ha survey units and intensively searched for indications of Key deer presence and areas of high use. Cameras were placed in areas of high use at a density of 1 camera per survey unit. Assuming seasonal ranges comparable to those observed by Silvy (1975), placement provided approximately 1.5 5.5 camera units per Key deer home range and offered complete coverage of Key deer habitat on each island complex. Commercially available Cuddeback digital infraredtriggered cameras (Non-typical Inc., Park Falls, Wisconsin, USA) were used to photograph Key deer. Camera density was 1 camera/sample unit ( $\sim 50$ ha) offering complete coverage of Key deer habitat on each island complex. Cameras were subjectively placed within sample units at sources of freshwater, along trails, in areas where Key deer or their sign were observed, or along likely travel corridors. Camerastations were baited once at initial setup with $\leq 3.81$ of domestic feed (e.g., sweet feed, cracked corn) to entice exploration by Key deer passing in close proximity to the camera station and maximize captures of individually identifiable Key deer. Cameras were operated simultaneously on each island complex for 20 consecutive 24 -hour periods (days). Date and time were automatically recorded on each digital photograph.

A 2-sample Peterson model (Seber 1982) was used to calculate abundance estimates using a 10-day mark and 10-day re-sight period. Bailey's binomial model (Bailey 1952) was used as it is more robust to small sample sizes (Seber 1982).

Resultant abundance estimates were then fit to a Poisson distribution and simulations were used to develop corrected population estimates using sightability of known deer on 
Cudjoe and Sugarloaf keys (70-100\%). Lower bounds of confidence intervals were adjusted to account for the minimum number known alive on each island complex and all fractions were rounded to the nearest whole number. Sightability of Key deer using cameras was analyzed using Program MARK (White and Burnham 1999) and ZeroTruncated Poisson Test of Equal Sightability (Caughley 1977). For a more detailed discussion of camera surveys see Chapter II.

Camera-based surveys were completed in close temporal proximity to FLIR surveys and I assume demographic and geographic closure between camera-based and FLIR-based surveys. Observed dispersal, movements, and mortality factors of Key deer on Big Pine Key (Lopez 2001, Lopez et al. 2003) support this assumption. Closure assumptions were further supported by monthly survival rates and locations of radiocollared Key deer on Cudjoe and Sugarloaf during this timeframe (100\%; Parker 2006).

\section{RESULTS}

Aerial-FLIR surveys occurred on 28 February-March 1, 2005 and 9-10 February, 2006 between 0630 and 0900 hours. Total area surveyed was approximately 3,472 ha yielding a total of 26 thermal signatures of Key deer in 2005 and 4,076 ha yielding a total of 27 thermal signatures in 2006 . Temperatures ranged from $15-24^{\circ} \mathrm{C}$ during surveys and were within the limitations of the FLIR system. Key deer thermal signatures were clearly visible and distinguishable under local conditions when Key deer were located in open areas. However, thermal signatures were more difficult to detect in dense vegetation. Aerial-FLIR surveys recorded 4 thermal signatures of Key deer on 
Cudjoe where an absolute minimum of 7 deer were known to be present during the 2005 survey. Similarly, 7 thermal signatures of Key deer were recorded on Sugarloaf in 2005 and 6 thermal signatures in 2006 where an absolute minimum of 12 Key deer were known to be present during surveys. Cudjoe was not surveyed in 2006 due to flight zone restrictions.

Cameras obtained 649 valid photographic captures of Key deer on outer islands. Sixteen of 19 (84.2\%) known individually identifiable Key deer inhabiting outer islands were photographically captured in 2005-2006. Cumulative capture rate for new individually identifiable deer reached asymptote around Day 9 and only 2 previously unidentified deer were captured after Day 10. Marked Key deer were regularly captured throughout the 20-day survey period at multiple camera stations. Mean capture of marked individuals during re-capture sessions was 2.7 and 2.4 for males and females respectively. Number of captures for individual marked Key deer ranged from 1-7 captures and results of Zero-Truncated Poisson Test of Equal Sightability indicated sightability by day was not equal among all individual Key deer $(P<0.001)$. Results of model selection using Program MARK indicated no significant difference in sightability by day between sexes (male $=0.244, \mathrm{SE}=0.031$; female $=0.224, \mathrm{SE}=0.019$ ).

Population estimates differed considerably between camera and FLIR survey methods (Table 3.1). Camera-based surveys consistently produced higher abundance estimates than FLIR counts. G-test results using camera derived estimates as expected values indicated that the number of deer observed using FLIR methods was significantly 
higher $(P=0.012)$ than population estimates derived from camera surveys using the Peterson estimator.

Table 3.1. Comparison of abundance estimates using infrared-triggered cameras and number of Key deer observed using aerial forward-looking infraredthermography methods, Lower Florida Keys, Florida, USA.

\begin{tabular}{lccccc}
\hline Island complex & $\begin{array}{c}\text { Total area } \\
\text { surveyed } \\
\text { (ha) }\end{array}$ & $\begin{array}{c}\text { Deer } \\
\text { observed } \\
\text { using FLIR } \\
(2005)\end{array}$ & $\begin{array}{c}\text { Deer } \\
\text { observed } \\
\text { using FLIR } \\
(2006)\end{array}$ & $\begin{array}{c}\text { Camera- } \\
\text { based } \\
\text { estimate } \\
2005-2006\end{array}$ & MNKA $^{\mathrm{a}}$ \\
\hline Cudjoe & 1,319 & 4 & $\mathrm{NS}^{\mathrm{b}}$ & 8 & 7 \\
Howe & 373 & 11 & 6 & 16 & 9 \\
Knockemdown & 582 & $\mathrm{NS}^{\mathrm{b}}$ & 5 & 9 & 3 \\
Little Pine & 382 & 4 & 7 & 12 & 4 \\
Sugarloaf & 1,399 & 7 & 6 & 25 & 12 \\
Torch & 1,341 & $\mathrm{NS}^{\mathrm{b}}$ & 3 & 38 & 10 \\
\hline
\end{tabular}

${ }^{a}$ MNKA, absolute minimum number of individual Key known to be alive.

${ }^{\mathrm{b}} \mathrm{NS}$, no survey was conducted.

\section{DISCUSSION}

Because these surveys were conducted on sub-populations of unknown size, it is not possible to compare accuracy between the 2 techniques. Camera-based surveys were a more cost effective method to obtain estimates of Key deer abundance on outer islands. The number of infrared-triggered cameras necessary for camera-based surveys varies with island size and cost per camera unit varies among manufacturers. A minimum of 9 cameras was needed to survey the largest island (i.e., Sugarloaf). In this study, initial 
investment for camera-based surveys was considerable-- approximately $\$ 330$ per camera unit. However, once purchased the long-term cost of operation per survey was negligible-- approximately $\$ 5$ per camera unit. Cost of the ThermaCAM ${ }^{\circledR}$ B-20 FLIR system was $\$ 28,000$. Surveying all outer islands required approximately $8-10$ hours of helicopter flight time, the cost of which would have varied from $\$ 350-600$ per hour depending on type of helicopter used. Cost estimates do not include technician salaries.

Forward-looking infrared thermography technology is currently of limited use in Key deer management. I suggest that camera-based surveys, despite the amount of field work and time required, should be the preferred method to survey outer islands. Utility of FLIR-based surveys appears to be limited by low sightability due to dense tropical vegetation. Physiological characteristics such as small body size and behavioral characteristics such as secretive and solitary tendencies also may appreciably reduce sightability of Key deer using FLIR technology. Surveys based on FLIR technology are typically conducted under the assumption of complete or nearly perfect detection (e.g., Havens and Sharp 1998, Wiggers and Beckerman 1993, Dunn et al. 2002). Thus, FLIRbased surveys require that all Key deer be detected as this method represents a minimum count. However, results of camera-based surveys and failed observation of known Key deer numbers (50-57\% of minimum known) indicate that only a small proportion of Key deer present on islands were detected using FLIR methods. It may be desirable to apply a correction factor for FLIR-based surveys of large mammals in tropical and sub-tropical environments or other areas exhibiting dense vegetation. 
Sightability of Key deer using FLIR technology may have been limited by local ambient temperatures. Havens and Sharp (1998) concluded that FLIR-based surveys offered adequate sightability of large mammals at $25^{\circ} \mathrm{C}$. Temperature during FLIR surveys were within the limitations of the FLIR system. Thermal contrast also was improved due to full or partial cloud cover during surveys. Key deer sighted using FLIR were clearly visible, also indicating ambient temperature was not a limiting factor. Although conducting FLIR surveys at night (Wiggers and Beckerman 1993, Garner et al. 1995, Graves et al. 1972) or pre-dawn (Havens and Sharp 1998) could provide improved thermal contrast of large mammals, night flights were not possible during this study due to flight restrictions. The utility of FLIR-based survey also may have been limited by the capabilities of the camera equipment used in this study and other FLIR systems might produce improved results. Further research is necessary to address sightability, correction factors, and limitations of specific equipment in sub-tropical and tropical environments. 


\section{CHAPTER IV}

\section{CONCLUSIONS AND IMPLICATIONS}

The purpose of this chapter is to summarize current methods to survey Key deer on outer islands. This chapter provides a general summary of the research presented in this thesis. Additionally, this chapter provides management recommendations regarding estimating Key deer sub-population abundances on outer islands.

\section{CAMERA-BASED SURVEYS}

Camera-based surveys offer a practical and accurate method to monitor the spatial distribution on Key deer throughout their range. Results of this study indicate camera-based surveys may provide a practical method to estimate and monitor Key deer abundance and population trends on outer islands. In addition, camera-based surveys can provide a method to evaluate the efficacy of management actions on outer islands such as translocations and habitat manipulations. Similar sightability among male and female Key deer and use of natural marks minimized the temporal and financial costs associated with conducting surveys of abundance on outer islands. In addition, methods presented here alleviate the need to capture and mark individuals, thereby minimizing invasive and potentially harmful management actions.

Camera-based surveys should be conducted in August-September allowing maximal discrimination of antler configuration, assumption of mark retention, and minimization of behavioral bias due to rutting behaviors. Although baiting may not be necessary, it is acceptable to bait camera stations at initial camera station setup only if 
the Peterson or Minta-Mangal estimators are used to estimate abundance. However, I recommend that camera stations not be re-baited during surveys as this may introduce further behavioral bias into population estimates. Surveys should be conducted for 20 consecutive days as this timeframe allows collection of sufficient data and capture of most individual Key deer. I recommend the addition of multiple recapture sessions to address inherent variability and address the accuracy of Key deer abundance estimates for individual islands. Camera density should be a minimum of 1 camera per 50 ha of Key deer habitat.

All methods used to develop abundance estimates presented in Chapter II are subject to biases associated with small samples sizes and sightability of individual deer. Sightability of individual Key deer is an inherent problem when estimating Key deer abundance using camera-based methods. Methods developed by Minta and Mangel (1989) address variability in individual sightability and I recommend the Minta-Mangal estimator be used when estimating Key deer abundance on outer islands. Additionally, I recommend further validation of camera-based survey methods for Key deer. Managers should be cognizant of potential biases inherent in camera-based estimates of Key deer abundance and derived estimates should be used with prudence in management of Key deer. A single estimate of population size provides little information about the status of a population (Lancia et al. 1996). Thus, I recommend camera-based surveys be conducted annually to monitor population status and trends on outer islands. If annual surveys are not feasible, I recommend the development of a rotational survey scheme 
which focuses on primary sub-populations such as Cudjoe, Howe, Little Pine, and Sugarloaf.

\section{FLIR-BASED SURVEYS}

I tested the utility of forward looking infrared-thermography (FLIR) technology to estimate abundance of Key deer on outer islands using aerial survey methods. Utility of FLIR-based aerial surveys appears to be limited by low sightability due to dense tropical vegetation. Although no test of accuracy was possible, results indicate that FLIR-based aerial survey methods are unreliable for the survey of large mammals in tropical habitats. Thus, FLIR-technology is currently of limited use in Key deer management and camera-based surveys should be the preferred method to survey Key deer abundance on outer islands. Physiological characteristics such as small body size and behavioral characteristics such as secretive and solitary tendencies also may appreciably reduce sightability of Key deer using thermal imaging. Results of known Key deer locations and survey method comparisons indicate that FLIR drastically underestimates Key deer abundance on outer islands. It may be desirable to apply a correction factor for FLIR-based surveys of large mammals in tropical and sub-tropical environments or other areas exhibiting dense vegetation. Use of aerial FLIR-based methods should be avoided when attempting to estimate Key deer abundance on outer islands. If aerial FLIR-based methods are used, I strongly recommend the development and application of correction factors for this type of survey. 


\section{MANAGEMENT IMPLICATIONS}

Reclassification of Key deer from endangered to threatened has recently been proposed as a result of increased Key deer densities at the core of their range (i.e., Big Pine and No Name keys; Lopez et al. 2004). Attempts to establish viable subpopulations (Parker 2006) address other recovery criteria (USFWS 1999). Other recovery criteria such as the evaluation of status and trends of Key deer on islands will also play a key role in the decision making process. Information from this study will be useful during evaluation of the proposed reclassification of Key deer. Data from this study also will facilitate appropriate management and conservation of the endangered Key deer metapopulation throughout their range.

Results of occupancy surveys using traditional and camera-based methods indicate that the distribution of Key deer has decreased slightly since the early 1970s. Absence of Key deer on previously occupied islands such as Big Johnson and Summerland keys may be an indication of population declines on outer islands. The effects of recent hurricanes and changes in freshwater quality are possible explanations for the observed constriction in distribution. However, metapopulations are dynamic and the absence of Key deer on specific outer islands may be the result of natural fluctuation in meta-population structure. Factors effecting the distribution and abundance of Key deer throughout their range (e.g., fresh water) warrant further investigation.

Relative abundance among islands raises questions as to the factors limiting Key deer abundance on outer islands. Abundance estimates for all islands were well below 
respective carrying capacities calculated by Lopez (2001). Islands such as Sugarloaf and Cudjoe have sufficient habitat and would be expected to maintain higher Key deer densities than observed. Furthermore, the absence of Key deer on previously occupied islands such as Big Johnson and Summerland keys is indicative of sub-population declines in nearby source populations. Research using models by Harveson et al. (2006) concluded that distance from source populations and island size significantly affects Key deer abundance on outer islands, and the results of this study support these conclusions. Larger natural populations of Key deer typically occurred on islands closest to Big Pine Key.

I recommend further evaluation of camera-based and other contemporary survey methods to estimate abundance of Key deer on outer islands. Future research needs include investigation of the general ecology of Key deer inhabiting outer islands. Primary emphasis should be applied to survival, fecundity, and recruitment on outer islands as these would be expected to have significant impacts on small local subpopulations. Dispersal rates (i.e., immigration and emigration) among outer islands also are important to the persistence of Key deer sub-populations and warrant further investigation. 


\section{LITERATURE CITED}

Akçakaya, H. R. 2000. Population viability analyses with demographically and spatially structured models. Ecological Bulletins 48:23-38.

Albon, S. D., H. J. Staines, F. E. Guinness, and T. H. Clutton-Brock. 1992. Densitydependent changes in the spacing behavior of female kin in red deer. Journal of Animal Ecology 61:131-137

Arnason, A. N., C. J. Schwarz, and J. M. Gerrard. 1991. Estimating closed population size and number of marked animals fro sighting data. Journal of Wildlife Management 55:716-730.

Bailey, N. T. 1952. Improvements in the interpretation of recapture data. Journal of Animal Ecology 21:120-127.

Boonstra, R., C. J. Krebbs, S. Boutin, and J. M. Eadie. 1994. Finding mammals using far-infrared thermal imaging. Journal of Mammalogy 75:1063-1068.

Bull, E. L, R. S. Holthausen, and L. R. Bright. 1992. Comparison of 3 techniques to monitor marten. Wildlife Society Bulletin 20:406-410.

Carbone, C., S. Christie, K. Conforti, T. Coulson, N. Franklin, J. Ginsberg, M. Griffiths, J. Holden, K. Kawanishi, M. Kinnaird, R. Laidlaw, A. Lynam, D. McDonald, D. Martyr, C. McDougal, L. Nath, T. O’Brian, J. Seidensticker, J. Smith, M. Sunquist, R. Tilson, and W. Wan Shahruddin. 2001. The use of photographic rates to estimate densities of tigers and other cryptic mammals. Animal Conservation 4:75-79. 
Caughley, G. 1977. Analysis of vertebrate populations. John Wiley and Sons, New York, New York, USA.

Caughley, G. 1994. Directions in conservation biology. Journal of Animal Ecology $63: 215-244$.

Croon, G. W., D. R. McCullough, C. E. Olson, Jr., and L. E. Queal. 1968. Infrared scanning techniques for big game censusing. Journal of Wildlife Management $32: 751-759$.

Cutler, T. L. and D. E. Swann. 1999. Using remote photography in wildlife ecology: a review. Wildlife Society Bulletin 27:571-581.

Dickson, J. D., III. 1955. An ecological study of the Key deer. Florida Game and Freshwater Fish Commission, Technical Bulletin 3, Tallahassee, Florida, USA.

Dunn, W. C., J. P. Donnelly, and P. J. Krausmann. 2002. Using thermal infrared sensing to count elk in the southwestern United States. Wildlife Society Bulletin 30:963-967.

Folk, M. L. 1991. Habitat of the Key deer. Dissertation, Southern Illinois University, Carbondale Illinois, USA.

Foresman, K. R. and D. E. Pearson. 1998. Comparison of proposed survey procedures for detection of forest carnivores. Journal of Wildlife Management 62:12171226.

Foster, M. L. and S. R. Humphrey. 1995. Use of highway underpasses by Florida panthers and other wildlife. Wildlife Society Bulletin 23:95-100. 
Fuller, T. K. 1991. Do pellet counts index white-tailed deer numbers and population change? Journal of Wildlife Management 20:451-453.

Garner, D. L., H. B. Underwood, and W. F. Porter. 1995. Use of modern infrared thermography for wildlife population surveys. Environmental Management 19:233-238.

Halley, R. B., H. L. Vacher, and E. A. Shinn. 1997. Geology and hydrology of the Florida Keys. Pages 217-248 in H. L. Vacher, and T. M. Quinn editors. Geology and hydrology of the Florida Keys. Elsevier, Amsterdam, Holland.

Halls, L. K. 1984. White-tailed deer: Ecology and Management. Stackpole Books, Harrisburg, Pennsylvania, USA.

Hanski, I. A. 1994. Patch-occupancy dynamics in fragmented landscapes. Trends in Ecology and Evolution 9:131-135.

Hanski, I. A. 1998. Metapopulation dynamics. Nature 396:41-49.

Hanski, I. A. and D. Simberloff. 1997. The metapopulation approach: its history, conceptual domain, and application to conservation. Pages 5-25 in I. A. Hanski and M.E. Gilpin, editors. Metapopulation Biology. Academic Press, San Diego, California, USA.

Hanski, I. A., J. Poyry, T. Pakkala, and M. Kuussaari. 1995. Multiple equilibria in metapopulation dynamics. Nature 377:618-621.

Harrison, S., D. Murphy, and P. R. Ehrlich. 1988. Distribution of the bay checkerspot butterfly, Euphydryas editha bayensis: evidence for a metapopulation model. American Naturalist 132:131-135. 
Harveson, P. M., W. E. Grant, R. R. Lopez, N.J. Silvy, and P.A. Frank. 2006. The role of dispersal in Florida Key deer metapopulation dynamics. Ecological Modeling 95:393-401.

Havens, K. J., and E. J. Sharp. 1998. Using thermal imagery in the aerial survey of animals. Wildlife Society Bulletin 26:17-23.

Hoffmeister, J. E., and H. G. Multer. 1968. Geology and origin of the Florida Keys: Geological Society of America Bulletin 79:1487-1505.

Jachmann, H. 2002. Comparison of aerial counts with ground counts for large African herbivores. Journal of Applied Ecology 39:841-852.

Jacobson, H. A., J. C. Kroll, R. W. Browning, B. H. Koerth, and M. H. Conway. 1997. Infrared-triggered cameras for censusing white-tailed deer. Wildlife Society Bulletin 25:547-556.

Karanth, K.U. 1995. Estimating tiger populations from camera-trap data using capturerecapture models. Biological Conservation 71:333-338.

Karanth, K. U., and J. D. Nichols. 1998. Estimation of tiger densities in India using photographic captures and recaptures. Ecology 79:2852-2862.

Kawanishi, K. 2002. Population status of tigers (Panthera tigris) in a primary rainforest of Peninsular Malaysia. Dissertation. University of Florida, Gainsville, Florida, USA.

Kindvall, O., and I. Ahlẽn. 1992. Geometrical factors and metapopulation dynamics of the bush cricket, Metrioptera-bicolor Philippi (Orthoptera Tettigoniidae). Conservation Biology 6:520-529. 
Klimstra, W. D., J. W. Hardin, and N. J. Silvy. 1978. Population ecology of the Key deer in P.H. Oehser and J.S Lea, editors. Research Reports, 1969, National Geographic Society, Washington, D.C., USA.

Klimstra, W. D., J. W. Hardin, N. J. Silvy, B. N. Jacobson, and V. A Terpening. 1974. Key deer investigations final report: December 1967-June 1973. U.S. Fish and Wildlife Service, Big Pine Key, Florida, USA.

Koerth, B. H., C. D. McKown, and J. C. Kroll. 1997. Infrared-triggered camera versus helicopter counts of white-tailed deer. Wildlife Society Bulletin 25:557562.

Krebs, C. J. 1999. Ecological methodology. Second edition. Addison-Welsey Educational Publishers Inc., Menlo Park, California, USA.

Lancia, R. A., J. D. Nichols, and K. H. Pollock. 1996. Estimating the number of animals in wildlife populations. Pages 215-253 in T. A. Bookhout, editor. Research and management techniques for wildlife and habitats. The Wildlife Society, Bethesda, Maryland, USA.

Langdon, C. A. 2001. A comparison of white-tailed deer population estimation methods in West Virginia. Thesis, West Virginia University, Morgantown, West Virginia, USA.

Levins, D. A. 1969. The nature of plant species. Science 204:381-384.

Long, R. W. 1974. Origin of the vascular flora of South Florida. Pages 28-36 in P.J. Gleason, editor. Environments of South Florida: present and past. Miami Geological Society, Miami, Florida, USA. 
Lopez, R. R. 2001. Population ecology of Florida Key deer. Dissertation, Texas A\&M University, College Station, Texas, USA.

Lopez, R. R., M. E. P. Vieira, N. J. Silvy, P. A. Frank, S. W. Whisenant, and D. A. Jones. 2003. Survival, mortality, and life expectancy of Florida Key deer. Journal of Wildlife Management 67:34-44.

Lopez, R. R., N. J. Silvy, B. L. Pierce, P. A. Frank, M. T Wilson, and K. M Burke. 2004. Population density of the endangered Florida Key deer. Journal of Wildlife Management 68:570-575.

Mace, R. D., S. C. Minta, T. L. Manley, and K. E. Aune. 1994. Estimating grizzly bear population size using camera sightings. Wildlife Society Bulletin 22:74-83.

Martorello, D. A., T. H. Eason, and M. R. Pelton. 2001. A sighting technique using cameras to estimate population size of black bears. Wildlife Society Bulletin 29:560-567.

May, R. M. 1973. Complexity and stability in model ecosystems. Princeton University Press, Princeton, New Jersey, USA.

May, R. M. 1974. Ecosystem patterns in randomly fluctuating environments. Progress in Theoretical Ecology 3:1-50.

McCullough, D. R. 1979. The George Reserve deer herd: population ecology of a K selected species. University of Michigan Press, Ann Arbor, Michigan, USA.

Meffe, G. K., and C. R. Carroll. 1997. Principles of conservation biology. Second edition. Sinauer Associates, Sunderland, Massachusetts, USA. 
Minta, S. and M. Mangel. 1989. A simple population estimate based on simulation for capture-recapture and capture-resight data. Ecology 70:1738-1751.

Naugle, D. E., J. A. Jenks, and B. J. Kernohan. 1996. Use of thermal infrared sensing to estimate density of white-tailed deer. Wildlife Society Bulletin 24:37-43.

Neff, D. J. 1968. The pellet-group count technique for big game trend, census, and distribution: a review. Journal of Wildlife Management 32:597-614.

Nettles, V. F., C.F., Quist, R.R. Lopez, T.J. Wilmers, P. Frank, W. Roberts, S. Chitwood, and W.R. Davidson. 2002. Morbidity and mortality factors in Key deer, Odocoileus virginianus clavium. Journal of Wildlife Diseases 38:685-692.

Otis, D. L., K. P. Burnham, G.C. White, and D.R. Anderson. 1978. Statistical inference from capture data on closed animal populations. Wildlife Monographs 62:1-135.

Parker, I. D. 2006. Effects of translocation and deer-vehicle collisions on Florida Key deer. Thesis, Texas A\&M University, College Station, Texas, USA.

Pimm, S. L., H. L. Jones, and J. Diamond. 1988. On the risk of extinction. The American Naturalist 132:757-785.

Pollock, K. H. 1982. A capture-recapture design robust to unequal. Journal of Wildlife Management 46:752-757.

Roberts, C. W., B. L. Pierce, A. W. Braden, R. R. Lopez, N. J. Silvy, P. A. Frank, and D. Ransom, Jr. 2006. Comparison of camera and road survey estimates for whitetailed deer. The Journal of Wildlife Management 70:263-267.

Schoener, T. W., and D. A. Spiller. 1987. High population persistence in a system with high turnover. Nature 330:474-477. 
Seber, G. A. F. 1982. The estimation of animal abundance and related parameters. Oxford University Press, New York, New York, USA.

Seydack, A. H. W. 1984. Application of a photo-recording device in the census of larger rain-forest mammals. South African Journal of Wildlife Research 14:1014.

Silver, S.C., L. E. T. Ostro, L. K. Marsh, L. Maffei, A. J. Noss, M. J. Kelly, R.B. Wallace, H. Gomez, and G. Ayala. 2004. The use of camera traps for estimating jaguar Panthera onca abundance and density using capture/recapture analysis. Oryx 38:1-7.

Silvy, N. J. 1975. Population density, movements, and habitat utilization of Key deer, Odocoileus virginianus clavium. Dissertation, Southern Illinois University, Carbondale, Illinois, USA.

South, A. 1999. Dispersal and spatially explicit population models. Conservation Biology 13:1039-1046.

Stith, B. M., J. W. Fitzpatrick, G. E. Woolfenden, and B. Pranty. 1996. Classification and conservation of metapopulations: a case study of the Florida scrub jay. Pages 187-215 in D. R. McCollough and C. A. Covelo, editors. Metapopulations and wildlife conservation. Island Press, Washington, D.C., USA.

Sweitzer, R. A., D.Vanvuren, I. A. Gardner, W. M Obyce, and J. D. Waithman. 2000. Estimating sizes of wild pig populations in the north and central coast regions of California. Journal of Wildlife Management 64:531-543. 
United States Fish and Wildlife Service(USFWS). 1999. South Florida multi-species recovery plan: Key deer recovery plan. U.S. Fish and Wildlife Service, Southeast Region, Atlanta, Georgia, USA.

White, G. C. 1996. NOREMARK: population estimation from mark-resighting surveys. Wildlife Society Bulletin. 24:50-52.

White, G. C. and R. A. Garrott. 1990. Analysis of wildlife radio-tracking data. Academic Press, San Diego, California, USA.

White, G. C., and K. P. Burnham. 1999. Program MARK: survival estimation from populations of marked animals. Bird Study 46(Supplement):120-139.

White, G. C., D. R. Anderson, K. P. Burnham, and D. L. Otis. 1982. Capture-recapture and removal methods for sampling closed populations. Los Alamos National Laboratory, Los Alamos, New Mexico, USA.

Wiggers, E. P., and S. F. Beckerman. 1993. Use of thermal infrared sensing to survey white-tailed deer populations. Wildlife Society Bulletin 21:263-268.

Wyatt, C. L., M. Trivedi, and D. R. Anderson. 1980. Statistical evaluation of remotely sensed thermal data for deer census. Journal of Wildlife Management 44:397402.

Zielinski, W. J., and T. E. Kucera, editors. 1995. American marten, fisher, lynx, and wolverine: survey methods for their detection. United States Department of Agriculture, Forest Service, General Technical Report PSW GTR-157, Albany, California, USA. 
VITA

DOMINIQUE ELIJAH WATTS

\section{ADDRESS}

Department of Wildlife and Fisheries Sciences

Texas A\&M University

2258 TAMU

210 Nagle Hall

College Station, TX 77843-2258

domwatts@yahoo.com

\section{EDUCATION}

Master of Science, Wildlife and Fisheries Science, Texas A\&M University, 2006

Bachelor of Science, Double Major, Wildlife Science and Fisheries Science, New Mexico State University, 2004

\section{WORK EXPERIENCE}

Biologist, U.S. Fish \& Wildlife Service, Alaska Peninsula/Becharof National Wildlife Refuges, 2006-present

Biological Technician, U.S. Fish \& Wildlife Service, Koyukuk/Nowitna National Wildlife Refuges, 2003

President, New Mexico State University Student Chapter of the Wildlife Society, 2002-2003

Treasurer, New Mexico State University Chapter of the American Fisheries Society, 2000-2001

Fly Fishing Guide, Los Rios Anglers, Taos, New Mexico, 2004-2005

Fly Fishing Guide, Vermejo Park Ranch, Raton, New Mexico, 2000-2003 